\title{
DISCURSO E ATUAÇÃO PROFISSIONAL: UMA ANÁLISE CRÍTICA
}

\author{
Sara Regina Scotta Cabral \\ saracabral@brturbo.com.br
}

\section{RESUMO}

O discurso pode ser analisado, em uma das suas três dimensões (Fairclough, 2001), com as ferramentas da gramática sistêmico-funcional (GSF). Este artigo tem por objetivo examinar depoimentos de alunas do curso de Pedagogia, habilitação em Supervisão Escolar, quando questionadas sobre os modos de atuação, como profissionais, fora da escola, para a melhoria das relações interpessoais. Foram coletadas dez respostas e nelas foi examinada a transitividade, em termos de processos, participantes e circunstâncias. Os dados obtidos foram posteriormente confrontados e, finalmente, fizeram-se inferências acerca dos resultados, os quais apontam para a prevalência de processos materiais e relacionais, e para a presença de Atores animados como agentes e como principal Portador o supervisor escolar. Pelos depoimentos, percebe-se que os sujeitos pesquisados vêem-se como responsáveis pelas ações supervisoras nas suas escolas e comunidades, para as quais buscam realizar ações do mundo concreto. Ao mesmo tempo, revelam a necessidade de aperfeiçoar-se pessoal e profissionalmente para o exercício do cargo que, em um futuro próximo, irão exercer.

\section{INTRODUÇÃO}

Dentre as práticas sociais que abrangem a área da Educação, as atividades universitárias apresentam especificidades, baseadas nos tipos de cursos oferecidos e nas áreas a serem investigadas. Os cursos de formação de professores, especialmente o curso de Pedagogia, preocupa-se com a formação de profissionais aptos a participarem de práticas educativas diversas, seja em atividades docentes ou em tarefas relativas à eficácia da organização escolar. Derivam daí as habilitações em Supervisão Escolar, Magistério das Matérias Pedagógicas do Ensino Médio, Magistério da Educação Infantil e Anos Iniciais do Ensino Fundamental, e Orientação Educacional.

O Supervisor Escolar é o profissional que busca articular todo o processo educacional de modo a garantir o ingresso, a permanência e o sucesso dos alunos, especialmente através de currículos que atendam às reais necessidades da clientela escolar.

Tal prática pretendida passa necessariamente por diversas práticas discursivas, as quais carregam os valores, as crenças e os conceitos que norteiam os diversos grupos sociais. Desse modo, é importante que se analisem os enunciados utilizados na comunidade discursiva de modo a inferir aspectos ideológicos que permeiam o discurso dessa comunidade.

Este artigo tem por objetivo analisar parte do depoimento prestado por dez alunas do curso de Pedagogia, ao término do primeiro semestre de 2005, na disciplina de Redação. Os pressupostos teóricos embasam-se em Fairclough (2001), Heberle 
(2000) e especialmente na gramática sistêmico-funcional de Halliday $(1994,2004)$. São examinadas dez respostas à indagação sobre a atuação do profissional para a melhoria das relações interpessoais fora da escola.

Os dez enunciados foram analisados tendo-se em vista a transitividade selecionada pelas acadêmicas no processo de construção de suas respostas. Investigaramse os processos, os participantes e as circunstâncias, elementos lingüísticos que podem sinalizar para a identificação dos valores que subjazem à camada verbal.

Este trabalho apresenta inicialmente os pressupostos teóricos da Análise Crítica do Discurso (ACD) e as bases da transitividade da gramática sistêmico-funcional. Logo após, os depoimentos são examinados quanto a três categorias (processos, participantes e circunstâncias) e, por fim, são apresentados os resultados obtidos.

\section{A ACD E A GRAMÁTICA SISTÊMICO-FUNCIONAL}

Bakhtin (1997, p. 279) afirma que "a utilização da língua efetua-se em forma de enunciados (orais e escritos), concretos e únicos, que emanam dos integrantes de uma ou de outra esfera da atividade humana". Esses enunciados estão carregados de indicadores das condições de produção, das características dos participantes e dos objetivos comunicativos do emissor. Daí a presença de recursos lexicais, fraseológicos, gramaticais e de construção das proposições.

Discurso, para Meurer (1997, p. 16) é "o conjunto de afirmações que, articuladas através da linguagem, expressam os valores e significados das diferentes instituições" Tais princípios necessitam apoiar-se na materialidade do texto, que "é a realização lingüística na qual se manifesta o discurso" (idem, ibidem). O discurso, por sua vez, "organiza" o texto e faz com que este último adquira características próprias, revestido de ideologias, propósitos e maneiras de lidar com a realidade.

As pesquisas em Análise Crítica do Discurso (ACD) têm se desenvolvido especialmente através das obras de Fairclough, van Dijk, Fowler, Kress, Wodak e Talbot. No Brasil, somente no último decênio as investigações iniciaram, em que se destacam Heberle, Figueiredo e Ostermann, entre outros. Por tentar explicar a relação que existe entre sociedade e linguagem, a ACD constitui o que se denomina lingüística crítica.

Pesquisadores da área procuram demonstrar como representações lingüísticas são afetadas por valores sociais e como determinadas visões da realidade preponderam em detrimento de outras. O uso da linguagem relaciona-se estreitamente com fenômenos sociais, pois as pessoas falam, escrevem, ouvem e lêem de maneira socialmente determinada, como membros de determinadas categorias sociais, grupos específicos, profissões, organizações (...) (Heberle, 2000, p. 291).

Os estudos de ACD (Fairclough (2001) propõem distinguir três efeitos construtivos do discurso: (i) a construção das identidades sociais: (ii) a construção das relações entre as pessoas e (iii) a construção de sistemas de conhecimentos e crenças. Tais efeitos são possíveis se vistos na perspectiva das práticas discursivas 
vigentes na sociedade. A metodologia proposta então pelo autor (idem) para a análise do discurso parte de uma concepção tridimensional, que engloba três instâncias: a prática sociocultural, a prática discursiva e o texto propriamente dito.

A prática social, de orientação econômica, política, cultural, está intimamente ligada aos sistemas de valores e crenças que permeiam todas as ações humanas. A prática discursiva, por sua vez, é uma forma particular da prática social, e está vinculada aos modos de produção, consumo e circulação do discurso. Já a análise textual é feita tendo por base os pressupostos da gramática sistêmico-funcional (Halliday, 1994, 2004), por proporcionar ao analista as ferramentas necessárias para evidenciar, na camada lingüística, as pistas para a identificação dos outros dois segmentos. Engloba elementos como organização da mensagem, transitividade, modalidade, itens lexicais, coesão e coerência, entre outros.

No que se refere à transitividade, o objetivo da análise é "verificar se tipos de processos e participantes particulares estão favorecidos no texto, que escolhas de voz são feitas (ativa ou passiva) e quão significante é a nominalização dos processos. Um dos maiores interesses está na agência, na expressão de causalidade e na atribuição de responsabilidade" (Fairclough, 2001, p. 287).

Transitividade, para Halliday $(1994,2004)$, é o sistema gramatical de que o falante/escritor lança mão para construir a experiência humana nos eventos comunicativos. A transitividade constrói o fluxo da experiência em sentidos e em palavras e é representada na configuração de processos que envolvam participantes e, eventualmente, circunstâncias

Os participantes do processo são as entidades envolvidas - pessoas ou coisas, seres animados ou inanimados. Exercem papéis como o de Ator, Beneficiário, Portador, Experienciador e outros. As circunstâncias referem-se às noções de tempo, modo, causa, lugar e outros. Os processos, em gramática funcional, são usados com dois significados: a) para se referirem ao que está acontecendo no todo da oração; b) para se referir à parte da proposição encapsulada no sintagma verbal. Podem ser divididos em três grandes grupos: material (processos de acontecer, criar, fazer), mental (processos de pensar, sentir e ver) e relacional (processos de atribuir, identificar, simbolizar). Além desses, três outros intermediários também são utilizados: verbal (processos de dizer), comportamental (processos de comportar-se) e existencial (processo de existir). Em gramática funcional, cada tipo de processo envolve diferentes tipos de participantes.

Vale ressaltar que a visão tríplice da transitividade repousa, na verdade, na distinção gramatical das classes de palavras em verbos, nomes, advérbios e outras categorias. De antemão, pode-se afirmar que os (i) sintagmas verbais, (ii) nominais e (iii) adverbiais correspondem a (i) processos, (ii) participantes e (iii) circunstâncias. Desse modo, processo, participante e circunstância são categorias semânticas que explicam, na maioria dos casos, como os fenômenos do mundo real são representados em estruturas lingüísticas (Halliday, 1994, 2004).

\section{ANÁLISE DO CORPUS}

São analisados neste artigo dez depoimentos de alunas de um curso de Pedagogia, habilitação Supervisão Escolar, matriculadas nos sexto, sétimo e oitavo semestres. $O$ corpus que aqui se examina foi colhido ao final do primeiro semestre 
de 2005, por ocasião da aplicação de um questionário escrito sobre as atividades realizadas na disciplina de Redação Técnica e correspondem à resposta a uma questão dentre 19 que foram solicitadas: "Em que situações você pode atuar, como profissional, para a melhoria das relações sociais fora da escola?" Nos depoimentos busca-se fazer uma análise das respostas, especialmente sob o ponto de vista da transitividade (Halliday, 1994, 2004). O objetivo principal é, através da identificação de processos, participantes e circunstâncias que compõem o material lingüístico, observar-se como as acadêmicas concebem a tarefa de Supervisor Escolar.

A seguir, são transcritos os dez depoimentos.

(a) Tendo um bom relacionamento com todos, principalmente com a família dos alunos.

(b) O principal é trazer os pais para escola, mostrar qual é o papel deles na educação de seus filhos. Envolver a comunidade na construção da política pedagógica da escola.

(c) Ser um parceiro dos alunos, pais e professores.

(d) Sendo uma cidadã responsável, crítica e consciente.

(e) Sempre elevando o nome da escola, nunca abrindo espaço para fofocas.

(f) Como uma cidadã consciente e atuante com ética e postura.

(g) Nas missas da comunidade, pedágios, festas da comunidade e referência pessoal e profissional pela minha postura perante os alunos, pais e comunidade pois moro na comunidade.

(h) O que mais prejudica as relações sociais (...) é a falta de respeito com o ser humano. Eu não preciso concordar com tudo e com todos mas eu devo respeito a todos. Portanto posso exemplificar com pequenos atos como não criticar os colegas, alunos ou pais sem que antes eles tenham a oportunidade de se defender, sempre tentar resolver os problemas entre eu e a pessoa a que ele diz respeito; não tomar uma crítica a respeito do trabalho como algo pessoal; ser cortês e gentil com todos principalmente com quem não tenho simpatia, enfim, tudo o que possa tornar o ambiente (...) mais agradável.

(i) Em situações onde possa intervir para o bem do aluno, ou seja, onde eu possa atuar com meus esforços profissionais, para que o educando possa mudar, ou tente mudar seu comportamento, gerando um processo de conscientização deste aluno dentro da Escola. O futuro começa nela, e nela que formamos para o pessoal; deste para o profissional; e deste para o social. Sem esquecer a função do psicólogo na Escola.

(j) Em primeiro lugar, conhecendo a comunidade, o contexto onde a escola está inserida. Fazer com que a comunidade participe das atividades promovidas pela escola. Promovendo reuniões, palestras abertas ao público.

A análise dos processos verbais evidencia o uso intenso de processos materiais (19) como em 'trazer' (b), 'mostrar' (b), 'abrindo' (e), 'intervir' (h), 'mude' (h) 'gerando' (h), 'promovendo' (i) e outros, seguido dos relacionais (12) como em 'tendo' 
(a), 'é' $(b, g)$, 'ser' $(e, g)$, 'tenham' $(g)$, 'tornar' $(g)$. Há também a presença de processos mentais (5) e verbais (3).

Os Atores constituem seres animados - 'o supervisor' (b,e,f,h,i), 'eu' (f), 'ele' (h), 'o educando' (h). -, inanimados - 'a escola' (i) - ou outros sintagmas nominais - 'o principal' (b), 'o futuro' (h), 'a comunidade' (i), 'o que' (g). Note-se que, dentre os participantes identificados como Meta, 'os pais' (b) representa seres animados e prevalecem sintagmas nominais como 'política pedagógica' (b), 'espaços' (e), 'as relações sociais' (g), 'seu comportamento' (h), 'um processo de conscientização' (h), 'as atividades' (i), 'reuniões, palestras abertas ao público' (i).

A escolha dos Portadores recaiu sobre 'o supervisor', subentendido em todos os enunciados ( $b, d, e, f, g, h, i)$, 'eu' (a, $f, g, h)$, 'o principal' (b), 'eles' (g), 'ele' (e) e pronomes como 'qual' (b) e 'o que' ( $g$ ). Já os Atributos selecionados foram 'um bom relacionamento' (a), 'o papel' (b), 'um parceiro' (c), 'uma cidadã responsável, crítica e consciente' (d), 'a falta de respeito' $(g)$, 'a oportunidade' $(g)$, 'cortês e gentil' $(g)$, 'simpatia' $(g)$, 'agradável' $(g)$, dentre outros.

Nos processos mentais - 'concordar' (g), 'tentar' (g), 'tomar [uma crítica]' (g), 'esquecer' ( $h$ ), 'conhecendo' (i), os Experienciadores escolhidos foram 'eu' $(g)$, 'o supervisor' ( $g$, i), 'nós' (h) e os Fenômenos, 'tudo e todos' $(g)$, 'os problemas entre eu e a pessoa' (g), 'uma crítica' (g), 'a função de psicólogo' (h), 'o contexto' (i).

Poucas circunstâncias foram utilizadas, a maioria de lugar - 'para a escola' (b), 'nas missas da comunidade, pedágios, festas da comunidade' (f), 'na comunidade' (f), 'na escola' (g), 'dentro da Escola' ( $h$ ), 'onde' (i) - e algumas de tempo - 'sempre' (e), 'nunca' (e) 'antes' (g) - e uma de companhia - 'com todos, principalmente com a família dos alunos' (a).

Além do observado, note-se que alguns dos enunciados das acadêmicas caracterizaram-se por uma preferência por certos processos: o enunciado (b) optou pelos processos relacionais e materiais, o enunciado $(h)$ por uma variedade maior de processos (materiais, relacionais, mentais e verbais), o enunciado (i) por sete processos materiais e um mental e o (j) por um mental e quatro materiais. Os enunciados menores optaram por processos relacionais (três) e materiais (dois).

\section{CONCLUSÃO}

A partir dos resultados obtidos, pode-se fazer algumas inferências quanto aos enunciados das alunas. Vale lembrar que eles respondem à questão: "Em que situações você pode atuar, como profissional, para a melhoria das relações sociais fora da escola?'

O elevado número de processos materiais e relacionais, como explicitado na seção anterior, leva a crer que, segundo as respondentes, a forma de atuação do profissional na promoção das relações interpessoais pode ser feita de duas maneiras principais: 1) através de ações concretas do mundo material como 'trazer', 'mostrar', 'fazer'; 2) através do cultivo de atributos qualificadores ('ser um parceiro', 'sendo um cidadão responsável', 'devo respeito', 'ser cortês e gentil'). Por outro lado, poucas serão as ações que requerem o trabalho de pensar, sentir e conhecer, ou mesmo de falar. Aí percebe-se que o uso da linguagem verbal não constitui o principal meio a ser utilizado para o atingimento dos objetivos propos- 
tos. A melhoria das relações sociais pautar-se-ia pela ação e pela qualificação de si.

Ao serem inquiridas sobre a atuação profissional, todas as dez acadêmicas colocaram-se no papel de supervisoras escolares, embora atualmente não o sejam, por trabalharem algumas como docentes em escolas de educação infantil e ensino fundamental e outras ainda não fazerem parte do magistério. Isso projeta o desejo das alunas em exercer a habilitação que estão cursando e a internalização dos valores, dos conceitos e das características de tal segmento profissional.

Os participantes em posição ativa são representados principalmente por 'o supervisor' e 'eu' (=supervisora), os quais estão encarregados de desencadear as ações de melhoria das relações interpessoais fora da escola. Está implícito aqui que pais, alunos, professores e comunidade escolar ocupam posição passiva, ao mesmo tempo que 'recebem', 'esperam' o trabalho do supervisor. Tais participantes passivos, exceto 'os pais' (b), são todos referentes ao mundo do supervisor, aos instrumentos, aos objetos de estudo ou ao campo de atuação de tal profissional ('política pedagógica', 'relações sociais', 'processo de conscientização', 'reuniões, palestras'). Desse modo, a ação supervisora não recairá sobre as personagens humanas da comunidade escolar, mas sobre entidades, processos e atividades.

O reduzido número de circunstâncias leva a crer que o espaço privilegiado de atuação é principalmente a escola, com alguma incursão fora de seus muros ('pedágios', 'festas da comunidade', 'na comunidade'), levando o leitor a entender que o raio de ação do supervisor limita-se à escola ou a lugares em que acontecem reuniões com fins beneficentes ou religiosos. Nota-se que a questão indagava sobre o que o profissional poderia realizar 'fora da escola'.

A análise acima descrita demonstra que o exame da camada lingüística, tendo por suporte a gramática sistêmico-funcional, pode conduzir a algumas conclusões em termos de valores, crenças e ideologia presentes por detrás dos enunciados. Ademais, tendo em vista os resultados obtidos, pode-se afirmar que o grupo de dez acadêmicas se vê não como professoras regentes ou funcionárias particulares que são, mas como supervisoras, únicas responsáveis pelo rumo das ações de melhoria das relações interpessoais fora da escola. A responsabilidade assumida é bastante grande e não tem em vista a interação com a comunidade, em processos constantes de troca. As boas qualidades deverão sempre ser cultivadas pelo supervisor, que mais age do que pensa e fala.

Os resultados podem conduzir à reflexão sobre qual é o verdadeiro papel do supervisor escolar hoje, tanto no seu ambiente de trabalho como nas relações sociais que mantém por conta de sua função. Não pode este profissional, sozinho, melhorar todo um processo que, sabe-se, é bastante complexo. Pode sim, o supervisor, articular ações conjuntas, fruto de reflexão profunda com seus pares e com a comunidade na qual atua.

\section{BIBLIOGRAFIA}

BAKHTIN, M. Estética da criação verbal. 2. ed. São Paulo: Martins Fontes, 1997. 
FAIRCLOUGH, N. Discurso e mudança social. Brasília: Editora Universidade de Brasília, 2001.

HEBERLE, V. Análise crítica do discurso e estudos de gênero (gender): subsídios para a leitura e interpretação de textos. In: FORKTAMP, M. B. M. \& TOMICHT, L. M. B. (org.). Aspectos de lingüística aplicada - estudos em homenagem ao professor Hilário Inácio Bohn. Florianópolis: Insular, 2000.

HALLIDAY, M. A. K. An introduction to functional grammar. 21. ed. London: Edward Arnold, 1994.

An introduction to functional grammar. London: Edward Arnold, 2004.

MEURER, J. L.; MOTTA-ROTH, D. O conhecimento dos gêneros textuais e a formação do profissional da linguagem. In: FORKTAMP, M. B. M. \& TOMICHT, L. M. B. (org.). Aspectos de lingüística aplicada - estudos em homenagem ao professor Hilário Inácio Bohn. Florianópolis: Insular, 2000. 